\title{
Higher Education Marketization: a Case of Language and Colliding Interests
}

\section{Tom S. Karlsson ${ }^{1}$ (D) - Susanna Karlsson ${ }^{2}$}

Published online: 10 June 2020

(C) The Author(s) 2020

\begin{abstract}
This article examines how market interests and state regulations come into play as policy makers engage in establishing language primacy within higher education (HE). More specifically, the focus concerns issues of internationalization within a multilingual context, manifested in language policies (LP). LPs are constructed in order to sort out which language to give primacy. Findings demonstrate how $\mathrm{HE}$ is balancing between invoking markets obfuscated through internationalization whilst simultaneously restricting market effects through state regulations. The promulgation of certain languages supports and weakens market and state interests. This article contributes to research and practice in HE, presenting future obstacles and challenges.
\end{abstract}

Keywords Higher education · Marketization · Internationalization · Language policy · Public policy

\section{Introduction}

One of the most common themes that have come to emerge when discussing contemporary contexts for higher education (HE) is that of internationalization. The concept of internationalization contains ideas about e.g. student and staff mobility (Brooks, 2018), a greater diffusion of research within and outside of national borders (Altbach, 2015; Jongbloed, 2003) and increasing the level of quality provided by higher education institutions (HEI) (Mwangi et al., 2018). A common theme adjacent with that of

Tom S. Karlsson

Tom.Karlsson@spa.gu.se

Susanna Karlsson

susanna.karlsson@svenska.gu.se

1 School of Public Administration, University of Gothenburg, PO-box 712, SE-40530 Gothenburg, Sweden

2 Department of Swedish, University of Gothenburg, Gothenburg, Sweden 
internationalization is that of forcing non-Anglophone countries into implementing English as a medium of instruction (EMI) (Duong and Chua, 2016; Siiner, 2016). More than that, English has become a prerequisite, a lingua franca (Salö, 2016; Swales, 1987) for HE, needed for becoming an actor on global education markets. With the advancement of managerialism and marketization of the public sector (cf. Mautner, 2010), competition has been launched as a primary factor for quality. Critical studies have demonstrated how recruitment texts for university positions have changed (Fairclough, 1993) and how an entrepreneurial thinking has come to emerge and dominate HE (Mautner, 2005). Marketization of HE has been viewed as a particularly interesting alternative to state regulation "because it defrays the fiscal cost" (Marginson, 2007 , p. 318), a process through which education transforms into a service like any other (Lynch, 2006). Internationalization, language primacy, and the move towards global educational markets are largely interconnected.

Market interests engage ideas about efficient use and allocation of resources. Producers and consumers are separated and exchange goods that are infused with certain associated values (Marginson, 2007). An underpinning idea of marketization resides in its focus on producing high quality products, fitted to consumers' needs. Such quality is assumed to be increased when producers (and consumers) interact on competitive arenas. Embedded in a neoliberal discourse (Robertson and Keeling, 2008), marketization of HE induces perceived needs for changing roles and contexts, where students as well as teachers become affected (Ball, 2004). State interests in HE are different. They encompass ideas about education being a public good, provided to citizens without rivalry and exclusion (Marginson, 2007). Ideas limited to efficient allocation of resources are complemented with more holistic ideas about collective efficiency through the effects of spill-overs, meaning that it will also affect those individuals that have not partaken in HE themselves (Lynch, 2006; Marginson, 2007).

In many countries, HE has traditionally been a public service provided broadly, financed by the state, and administrated and executed by public organizations. In Sweden, HE is an integrated part of the public sector. HEIs in Sweden are government agencies, required to comply with state regulations in a number of different contexts. For this article, one of the most relevant regulation concerns that public authority has to be carried out in Swedish. This means that whenever HE makes decisions that will impact citizens, they have to be made in the national language. At the same time, HE is charged with tasks of increasing internationalization. As indicated above, this often demands an implementation of English as medium of instructions (EMI) together with recruitment of international students and staff. Faced with the obligation of public authority in Swedish, HEIs have constructed local language policy (LP) documents, stating what language should have primacy in certain contexts. This situates HE between conflicting rules, where compliance with state regulations demands and rejects marketization.

The purpose of this article is to demonstrate how internationalization has become manifested in a multi-lingual context as a balancing act in LPs at HEIs in Sweden. This article thereby aims to widen current understandings of how HE in multi-lingual contexts, through the construction of policies, positions itself in a situation of concurrently embracing (i) market interests and (ii) state regulation.

The remainder of this article is structured as follows. In the next section the concepts of internationalization and marketization are discussed. The argument that 
internationalization is marketization in guise is developed, and it is demonstrated how marketization draws on an embedded nature of neo-liberal discourse (Robertson and Keeling, 2008). A discussion of methods follows, and extracts from the LPs are presented and analyzed. The article is concluded with a discussion of how HE is constructed as balancing between state and market in the LPs and implications of this construction are discussed from a practical and theoretical perspective.

\section{Literature Review}

Internationalization refers to the idea that HEIs have an obligation to work towards increased transparency and dissemination of research that reaches outside of the university itself as well as the nation's borders. However, the concept has become diluted in that it is rarely specifically defined in literature (Mwangi et al., 2018). Internationalization refers to a number of different reforms and policies that collectively intend to handle or cope with global trends (Altbach, 2015). Such reforms have been implemented with the purpose of facilitating student mobility (Brooks, 2018) and aligning HE curricula across nations (Cardoso et al., 2011). Duong and Chua (2016) draw on Maringe (2009) in explicating the concept. They argue that internationalization entails strategies of standardizing curriculum, intensifying student recruitment as well as staff recruitment, working with staff professionalization, and issues of funding. Brandenburg and De Wit (2015) define internationalization similarly, arguing that it is intended to make HEIs focus on exchange, mobility, and recruitment. From this perspective, internationalization has come to be understood as doing something good as to compared to e.g. globalization, which is understood as bad (Brandenburg and De Wit, 2015).

In Europe, internationalization as a theme for HE can be understood to have risen with the advent of the European Union (Altbach, 2015) and the instigation of the Bologna process. Specifically, the latter included ideas of aligning curriculum across member states in order to increase student and staff mobility (Cardoso et al., 2011). Although there were commendable intentions inherent in these reforms, they were underpinned by ideas of competition between HEIs from a global perspective. In this article, the Bologna process is understood as being part of a global trend of HE marketization. Marketization in this context thus concerns the process of understanding HE (Brandenburg and De Wit, 2015) and curricula (De Vita and Case, 2003; Knight, 2015) as tradeable commodities, transforming HE into a service like any other (Lynch, 2006).

Understanding internationalization from the perspective of marketization has paved the road for an increasing critique against the reforms. Knight (2015) e.g. argues that internationalization risks leading to an elitist situation, where HE is made both exclusive and excluding. Such a process of transforming HE into being excludable would risk leading to a commercialization and increase of so called degree mills with low quality providers. Brooks (2018) argues that internationalization inevitably draws on marketization, which will lead to an homogenization of HE. The rationales of marketization risk augmenting rivalry and exclusion (Lynch, 2006) which affects pedagogical practices (Molesworth et al., 2009), the meaning of teaching and learning (Ball, 2004), and even the very purpose of $\mathrm{HE}$ as a public production (Marginson, 
2007). Even more critical may be that internationalization contradicts its initial purpose. As internationalization has become connected with ideas of competition, HE are increasingly closing themselves in order not to lose competitive advantages, leading to a decrease in transparency and openness (De Vita and Case, 2003). HE which closes itself by focusing primarily on communicating with peers rather than the surrounding society may in turn end up losing legitimacy (Taylor, 2001; Ek et al., 2013; Lynch, 2006). Internationalization, then, ironically challenges the very idea of $\mathrm{HE}$ as places of free thought, debate, and scholarship.

This article focuses on how LPs concerning language primacy are constructed and how internationalization becomes manifested. Most commonly, this means an implementation of EMI within HEIs, as English has increasingly become a lingua franca around the world (Swales, 1987; Salö, 2016). For teaching purposes, English is preferred as it enables ideas of student (and staff) mobility. In a study of implementation of EMI in a Vietnamese context, Duong and Chua (2016) argued that the potential success depended on the proficiency of teachers as well as students. By extension, this means that internationalization may endanger the quality of education in multi-lingual contexts if the competence amongst teachers and students is not sufficient for deep discussions in a second (or third) language. The integration of EMI together with recruitment of international staff, can also lead to difficulties on a professional level. Studying how Danish HEIs worked with LPs, Siiner (2016) found that increased internationalization led to difficulties in organizing and integrating staff and instigated two distinct and conflicting language regimes. On the one hand English augmented the process of internationalization as more international staff could be welcomed to the organization. On the other hand, English as language primacy led to difficulties with fully integrating staff into the Danish society. From this perspective, turning to English as primary working language within an inherently non-English context could mean disconnecting organizational and national cultures.

This article argues that the marketization of HE is embedded in a wider neo-liberal (Robertson and Keeling, 2008; Fairclough, 1993) discourse. Neo-liberal in this sense refers to implications drawn from a market view of citizenship, an assumption that citizens are economic maximizers and that individuals are held responsible for their own well-being (Lynch, 2006; Marginson, 2007).

It is imperative to understand the context of $\mathrm{HE}$ as public organizations in Sweden. In Sweden, HE is an integral part of Swedish government. The Swedish government organizes, controls and finances HE through public organizations. A majority of HEIs in Sweden are government agencies, meaning that the employees within these agencies are civil servants. Although it is not the focus of this article to discuss the roles of civil service as such, one implication needs to be discussed: the responsibility of civil servants' compliance with state regulations. According to the constitution, civil servants in Sweden are considered autonomous implementers of policy, meaning that members of parliament or Government cannot intervene in daily operations. Within HE, roles of civil servants amongst lecturers become more complex. Not only are they teachers and researchers, they are also administrators, charged with duties of compliance with the Government. In addition, the multi-lingual context that characterizes an internationalized HE becomes challenged as administrative law and restrictions are engaged (Karlsson and Karlsson, 2019). Understanding that lecturers within HE in Sweden are also civil 
servants within the public sector serves as a way to understand multi-lingual context of market interest and state regulation.

\section{Methodological Approach}

The purpose of this article is to demonstrate how internationalization has become manifested in a multi-lingual context as a balancing act between (i) market interests and (ii) state regulations in LPs within HE in Sweden. At the time of this study, 21 (out of 48) HEI had adopted a language policy (Table 1). Documents for these 21 institutions were collected during 2015 and 2016, from the universities' websites, or from the registrar's offices. The earliest document was from 2006 and the latest was from 2016.

All of the collected documents were manually coded, addressing the purpose of the study (Auerbach and Silverstein, 2003). This meant that passages that explicitly or implicitly discuss internationalization and language preferences in HE were identified. The analytical approach was inductively iterative (Charmaz, 2006), meaning that passages were continuously revisited, facilitating a reinterpretation and recontextualization of the texts (Hammersley and Atkinson, 1995). An important part of the analysis draws on an intertextual approach (Hult, 2015) recognizing the connections between discourses and texts (Candlin, 2006). This meant that the analysis

Table 1 LPs included in the study (cf. Karlsson and Karlsson 2019)

\begin{tabular}{|c|c|}
\hline HEIs & Year \\
\hline Göteborgs universitet & 2006 \\
\hline Kungl. Konsthögskolan & 2007 \\
\hline Handelshögskolan i Stockholm & 2009 \\
\hline Högskolan i Borås & 2009 \\
\hline Högskolan Väst & 2009 \\
\hline Kungl. Tekniska högskolan & 2010 \\
\hline Linköpings universitet & 2010 \\
\hline Sveriges lantbruksuniversitet & 2010 \\
\hline Malmö högskola & 2010 \\
\hline Stockholms universitet & 2011 \\
\hline Södertörns högskola & 2011 \\
\hline Mittuniversitetet & 2012 \\
\hline Umeå universitet & 2012 \\
\hline Chalmers tekniska högskola & 2013 \\
\hline Karlstads universitet & 2013 \\
\hline Högskolan Dalarna & 2013 \\
\hline Linnéuniversitetet & 2014 \\
\hline Lunds universitet & 2014 \\
\hline Gymnastik- och idrottshögskolan & 2015 \\
\hline Högskolan i Halmstad & 2015 \\
\hline Konstfack & 2016 \\
\hline
\end{tabular}


focused on identifying segments and passages in the texts that related to internationalization and language primacy in different settings, then relating such passages to similar passages in other texts. The use of (i) market interests versus (ii) state regulation are theoretical constructs used in order to structure policy makers' empirical engagement of capturing and manifesting language preferences within HE. All exhibited extracts have been translated from Swedish into English.

It should be stressed that this study has not included the actual implementation process or the language practices engaged within HEI. This means that this study cannot say if the LPs have had any effect on HE language practices. Other scholars are urged to pick up on this, and undertake practice-oriented research advancing from arguments and findings presented in this article.

\section{Language Primacy in Multi-Lingual Contexts}

During the early 2000's, two important reforms were introduced and implemented in Swedish HE. Firstly, the idea of internationalization was advanced by the Swedish Government in its bill (Prop. 2004/05:162) "New World - new higher education". It was argued that HE needed to be more attractive, with higher quality, and striving towards a widened recruitment. Internationalization was framed as a need to compete with or against HEIs in other European nations. The Bologna process that was being tolled out within the European Union during the 1990's exposed the need to attract employees as well as students from other countries (Cardoso et al., 2011). Secondly, the Swedish government became increasingly interested in securing Swedish as a primary language. Up to this point in time, Swedish had been implicitly recognized as the primary language, but it was argued that its status needed to be formalized in law (SOU 2002:27). Following this, the parliament passed the Swedish Language Act, that states that the "language in courts, administrative agencies and other bodies that fulfill tasks within public organizations is Swedish" (SFS 2009:600).

For HE in Sweden, this proved to be problematic. Should they fully embrace ideas about internationalization with all that it entails in terms of shifting focus to English, or should they comply with being government agencies employing civil servants that were required to communicate in Swedish? The core argument conveyed here is that the two reforms effectively juxtaposed HE between two independent and differently purposed legislations. On the one hand, internationalization required a presence on a global market where they were assumed to compete for resources: employees and students. In order to make that possible they needed to adopt English as a primary language. On the other hand, exercising public authority required them to give Swedish primacy.

LPs within HE should be understood from this backdrop. It became necessary for HEIs to formulate how and when certain language primacy was desired or demanded. Following the demand of increased internationalization, several HEIs found themselves being forced into publishing and teaching in another language than their native one. The primary language in most cases came to be English, although policies indicate that the choice should be based on the language that the research and researcher benefits the most from. The two following extracts reveal two different constructions: 
Researchers and postgraduate students in each field are required to follow national and international linguistic practices within their specific fields. However, the use of Swedish as a working language is encouraged with regard to research that takes place in Swedish culture and the working environment and which aims to provide Swedish development in its area. (HV 2009 s.3)

In education at research level and within research, the languages should be chosen that best respond to the needs of the business. In accordance with the University's special responsibility under the Language Act, research may also be presented in Swedish. (LiU 2011 p. 1)

The first extract stresses the following formulation; "follow practice", which indicates the need for adhering to an external party. Such external parties could be fellow researchers, as well as external reviewers or potential students. Even though individuals are free to choose which language this is, the choice of adding that "use of Swedish as a working language is encouraged", indicates that international practice trumps national practice, in that other languages than Swedish are expected to be the norm. The second extract is stronger. The wording here is that the choice of language should "respond to the need of the business" followed by a sentence clarifying that research "may also be presented in Swedish". The fact that the policy stresses that researchers should also be able to present their research in Swedish, implies that other languages are of primary interest. Studies (Duong and Chua, 2016; Siiner, 2016; Salö, 2016) have demonstrated that within the context of internationalization, English is gaining prevalence within education as well as in research. Scholars write and communicate research in English in order to expand the potential spread and education is increasingly undertaken in English. This indicates that internationalization as an underpinning idea is present in the policy documents.

Internationalization builds on ideas about marketization and working within competitive segments of education. As has been discussed previously, recruiting top researchers and international (paying) students is a crucial task for HEIs. This is evident in the two extracts above. However, the promulgation of other languages than Swedish proves to be problematic in other instances of HE. This is most evident in passages where policy touches upon public authority, where Swedish is a legality-bound requirement.

The University of Borås is a government agency. According to legislation, government agencies are required to use the Swedish language. (HB 2009 page 1)

The vast majority of HEIs in Sweden are government agencies. Such public organizations are required to exercise public authority in Swedish, regardless of circumstances. In the above extract, this legality-bound context is manifested in stating that the "required [...] language to be Swedish". Since University of Borås is a government agency, there is no discretion. Abiding to the constitution requires giving Swedish primacy. The position of Swedish as the only language based in current legislation, contradicts the process of internationalization. Furthermore, it highlights how different interests emerge within the document. On the one hand, internationalization is portrayed as a necessity within competitive markets. English, specifically, is 
understood as the main language. On the other hand, public authority requires adherence to legislation. Under such circumstances, Swedish is the only option.

A strict interpretation of legislation, as is indicated in the above extract, inhibits any use of English when exercising public authority. From a practical perspective, such a stance is difficult to maintain. Especially within an internationalized environment. For this purpose, there are exemptions within LPs. The following three extracts are examples of such exemptions:

The meetings of the university board, faculty board (counter), institutional board, board of libraries and other work units, and bodies working on a delegation from or as preparatory bodies for the said boards are in Swedish. At the meeting of the Board of Appeal, the chairperson may decide that the processing of a particular case shall be in English if a non-Swedish-speaking expert participates in the meeting. (LIU 2010 p. 2)

Meetings of decision-making and preparatory bodies shall be held in Swedish unless circumstances require English or other languages. Such a circumstance is the meetings of international rapporteur, or meetings of the employment committee with international experts present. (MAH 2010 p. 2)

Since Karlstad University is a Swedish authority, the language of the meeting is usually Swedish. This is especially true of meetings of all preparatory and decision-making bodies, but should also be taken into account for institutional and subject meetings. Deviations may occur if circumstances so require. Individual opinions can always be presented in English by speakers who choose this in order to better express their views. (KAU 2013 p. 6)

In contrast to internationalization, Swedish is given primacy during meetings within the university. As demonstrated above, Swedish is understood to be a legality-bound requirement within administrative functions. In the above extracts, three exemptions from this requirement are constructed. Within the first extract, it is stated that English may be used, if the president decides so, in specific matters within the employment board where non-Swedish speakers participate as experts. By exclusion, this implies that matters that are to be handled outside of the employment board has to give Swedish primacy. The second extract, from Malmö University, is constructed similarly, with the addition that other meetings where international reciters have been invited may be held in English. In both extracts, it is clear that normal use is Swedish, and only under certain invitations may another language be used. This implies that the possibility to use English in administrative functions is not an a priori situation, but an exemption from normality.

Karlstad University provides a slightly more pragmatic stance, stating that "deviations may occur if circumstances so demand" and that "individual opinions can always be presented in English by speakers who choose this". Two things are of specific interest for this analysis. Firstly, the use of any other language than Swedish is considered to be an exemption (deviations in the document). The construction of other languages as being exemptions highlights that Swedish is the primary language. Secondly, as an example of a viable exemption, English is progressed in the extract. It is stated that "individual opinions can always be presented in English", implicating English to be the primary exempted language. In a sense, the deviations implemented in 
this extract can be understood as a way to cope with state regulations and market interest in multi-lingual contexts. State regulations mark the primacy of Swedish, but market interests demand exemptions that redefine English as a possible language even in administrative meetings.

Although the above extracts reveal some examples of exemptions from the primacy of Swedish, a close reading of the documents reveal how certain aspects of public authority cannot be exempted. It is one thing to create contexts wherein English (or other languages) can be used, and a different thing to make exemptions from legislation. This becomes evident in the following extracts:

For meetings in a language other than Swedish, protocols must be written in Swedish and English. Regardless of protocols or other types of documents, it is the Swedish version that is legally binding, while the English is to be considered a translation. Translations must be made in such a way that no part of the content of the document is lost. In cases where decision-making is in a language other than Swedish, the decision should be sufficiently formulated that even a person who cannot fully understand the whole, must understand the meaning of the decision. (SH 2011 p. 28)

Examination is the exercise of authority. Students should therefore always be entitled to submit their answers in Swedish if they do not apply to language and linguistic terminology, regardless of the language used primarily in teaching. (KTH 2010 p. 6)

The first extract states that if exemptions to undertake meetings in Swedish are exercised, minutes have to be taken in both Swedish and English. However, the legally binding document is always Swedish, never the English one. The English version is to be understood as a translation, i.e. a secondary version. Both of these positions enforce the context of giving Swedish primacy as discussed above. The second extract focuses on the activity of examining student tests. The policy states that students "always have the right to leave their answers in Swedish upon examination" regardless of which language has been used during lectures. The only exemption to this is such cases where the actual test is on language proficiency. The reason for this far-reaching student right is that examination fundamentally is a task defined as exercising public authority. Such activities cannot be given any exemptions. This means that even though whole classes are given in English, the examination as such can be undertaken in Swedish. This gives Swedish students an advantage over non-native English-speakers when enrolled in international classes, as Swedish students have a right to use their native tongue; while a small part of international students might have English as their strongest or primary language, it is likely that most of them study in a language that they have learned as a secondary school language. This provides us with an example of how internationalization in a multi-lingual context can be understood to be hindered by existing state regulation (Newman and Jahdi, 2009). The requirements discussed in this analysis also constitute a structural impediment in regards of career for individual researchers.

Teachers who do not know Swedish have difficulty meeting the requirements and are usually not in charge of management assignments. (KTH 2010) 
In this extract, Swedish is a prerequisite for management duties. This implies a severe limitation for junior (international) academics, as management duties are a necessary prerequisite for academic promotion. Poor understanding and ability to speak, write, and communicate in the dominant language within multi-lingual contexts comprises contexts wherein negative structural impediment counteract internationalization. However, there are further embedded implications. Just as international non-Swedish speakers are at risk for experiencing a lock-out effect in the form of negative structural impediment as a result of giving Swedish primacy, native Swedish speakers risk a lockin effect, as they have the necessary skills for taking on managerial tasks. That is, Swedish speaking researchers employed within a faculty primarily consisting of international non-Swedish speaker's risk getting stuck in management duties. Such management duties may jeopardize individuals' ability to acquire merits through research.

As such, contemporary market interests and state regulations coexist within and between LPs in HE. It has been demonstrated how different public organizations engage in a balancing act between these two instances, trying to handle emerging conflicts. In the following discussion, the empirical analysis will be qualified and it will be argued that although English is promoted as a lingua franca for the internationalized $\mathrm{HE}$ it is met with resistance through state regulations.

\section{Discussion}

Marketization has been dominating HE since the beginning of the Bologna process during the 1990s. For HE, this has come to mean a focus on student and staff mobility (Brooks, 2018), increased competition (Altbach, 2015; Jongbloed, 2003), and a commodification of curriculum (De Vita and Case, 2003). The context of HE as institutions of learning is jeopardized as degree mills (Knight, 2015) emerges. Marketization has given rise to concerns of transforming $\mathrm{HE}$ into a rivalry and excludable good (Marginson, 2007), where both product and consumer are questionable (Marginson, 2007) and the market in itself quite elusive (Lynch, 2006).

The empirical data gathered from 21 LPs reveals the manifestation of marketization in the form of internationalization. In a context wherein learning is commodified, individual HEIs cannot resist participation if they wish to retain their current position. The ongoing competition of resources highlights the need to promulgate ideas about being innovative, novel, groundbreaking. Mautner (2005) refers to this as the entrepreneurial university. This promulgation cannot be undertaken without a clear and convincing communication. By convincing their immediate surroundings that they, the specific HEI, is world leading in certain areas, stories that attract new students, staff, and even financiers are facilitated. Students are to a large degree reconstructed into consumers rather than co-producers of learning (Ball, 2004; Knight, 2015; De Vita and Case, 2003).

This article argues that a core idea inherent in the market concerns the efficient allocation of resources. This occurs when a good is subjected to exchange between providers and consumers, and that a value is associated with the good (Marginson, 2007). Efficient allocation of resources also stresses that providers and consumers compete with each other in order to eliminate other producers from the exchange. This means that a key factor for marketization concerns the transformation of HE into a 
private good, with rivalry and excludability. HEI which participate in this process align with the trend of transforming learning into something that is preserved for the few. State interests, however, are different in that it primarily regards education and learning as a public good, that should be provided to all citizens without rivalry and exclusion (Marginson, 2007). From this perspective, efficient allocation of resources is not limited to competitive markets but take into consideration such factors as spill-over, where the collective efficiency in society is enlarged by educated citizens. HE, from a state interest, thereby embraces ideas that education will also affect the level of efficiency amongst individuals that have not themselves participated in HE, meaning that there are positive effects of education in society at large.

In order to develop the arguments presented in this study, findings are discussed under two topics; (i) a general strive for internationalization and (ii) administrative restrictions. Findings suggests that although HEIs have adopted the idea of internationalization, several functions inherent in public authority function as an obstacle for marketization.

This study of LPs naturally focuses on language. More specifically, the analysis reveals how different languages are given primacy in different contexts. An implication of this is that the contexts of teaching and research are deeply embedded in ideas of marketization, wherein choice of language is deeply important, as it constructs an external recipient to public organizations. Research should be undertaken and communicated in a language that can be understood by many recipients. In most cases, the choice of such a language will be English. It is clear that giving English primacy increases the opportunity for internationalization. It is also clear that the choice of English is more than that. It has been demonstrated how the choice of language is not primarily about communicating with other scholars or the surrounding society, but resonates against a "need of the business".

This "need of the business" in connection with premiering English as a lingua franca can be understood as an alignment of HE with a marketization agenda (Altbach, 2015). It is believed that HE competes with other institutions on a national as well as a global level, wherein students, teachers, and researchers are assets to be obtained. Competing within a globalized, or internationalized, environment demands that teaching is undertaken in English to facilitate student mobility. The pressure of teaching and organizing education in other languages than Swedish emanates from the increased presences of international students (Salö, 2016). In a competitive market, English is required in order for Swedish HE to be acknowledged by non-Swedish recipients. The actual choice of language primacy becomes a strategic choice for actors within HE, as they have come to internalize the idea of competitive markets and commodification of learning (Knight, 2015; De Vita and Case, 2003).

The need for English as a competitive market language is met with resistance within the LPs. In documents from e.g. the University of Borås, it is revealed that the HEI is a public organization abiding to Swedish constitution, meaning that Swedish has to be given primacy. This strict rule-abidance is devastating for HEIs wishing to expand their domains through internationalization as it hampers their ability to actually partake in global markets. The primacy of Swedish for authorities is based on an understanding that all citizens should understand exercised public authority. The basis for this is found in legal requirements, which demands clear and transparent language use. The LPs are themselves understood as emerged from this requirement, in which it needs to find a 
balance between different legal requirements in multi-lingual contexts. The analysis reveals that HEIs in Sweden acknowledge a need to give different languages primacy in different contexts.

This study argues that the strive for internationalization is being hindered by requirements of speaking and understanding Swedish as formulated by lawmakers. The LPs can from certain aspects be understood as a form of bureaucratic impediment and response to marketization (Poole, 2016). These impediments can be understood as the clashing of different interests, referred here as market and state, which leads to a number of challenging situations within HE.

Firstly, marketization requires a reconstruction of students into customers, and colleagues into contributors on a competitive market. This process of recruiting students, teachers, and researchers from international milieus leads to an increased level of people lacking ability to engage in activities requiring national language proficiency. Market and state mechanisms collide on this point in that public authority has to be carried out in Swedish. For those teachers and researchers that lack sufficient ability in Swedish, future contributions to management positions is severely hampered. KTH are clear, stating that those "...who do not know Swedish [...] are usually not in charge of management assignments". Depending on the level of internationalization that characterizes the institution, this carries different implications. For people that are early in their career, and does not have sufficient proficiency in Swedish, the colliding interests may function as a stop for future career development. The Swedish system requires administrative experience in order to be qualified for applications regarding full professorship, and with the demands of having to do this in Swedish it may prove difficult. Similar findings, although in a Danish context, have been discussed by Siiner (2016).

For people who have been recruited later in their career, lacking proficiency in Swedish may turn out to be a factor used in order to avoid being dragged into managerial duties. People already holding a full professorship are not driven by career incentives to improve their Swedish, as this would jeopardize the time they have available to undertake internationally competitive research. People that do have a high level of proficiency in Swedish within faculties that are highly internationalized are more likely to be recruited to management positions which could give positive effects for the career. However, if these individuals are not allowed to leave their positions within a reasonable time frame there is a great risk that they will end up falling behind in terms of research output.

Secondly, this study argues that the one-sided perspective of what is constructed as international - i.e. what is communicated in English - endangers a number of important disciplines within HE. The idea of publish-or-perish, which has come to characterize $\mathrm{HE}$ in the wake of marketization (Lynch, 2006) in combination with giving English primacy creates a bias for disciplines that are easily transferred into other national and governmental contexts. The natural and social sciences (for the most part) come out on top. These disciplines can for the most part be readily transformed into other settings. Disciplines that are of a more local character or focusing on topics that are not directly appropriate for communication through English are sorely losing the battle. Within competitive markets it is assumed that efficient allocation of resources leads to the best use. But, as accurately pointed out by Marginson (2007), marketization augments rivalry and exclusion and leads to public goods being perceived as less important. By merely measuring the profitability of a discipline, the humanities and critical disciplines run the risk of being severely weakened (Lynch, 2006). 


\section{Concluding Remarks}

The purpose of this article has been to demonstrate how internationalization has become manifested in a multi-lingual context as a balancing act in LPs at HEIs in Sweden.

This has been done through a study of LPs that explicitly tackle issues of when certain languages are given primacy. It has been demonstrated how the promulgation of a certain language in the LPs supports or weakens both state and market interests. Internationalization in regard to education is a manifestation of how marketization has taken a firm grip on HE. The pressure of teaching and organizing education in other languages than Swedish emanates from the increased presence of international students and staff. Yet, Swedish is understood as the only language in which public authority has legal binding. This means that internationalization carries implication for both native and non-native speakers of Swedish in terms of career opportunities.

Internationalization as presented in the LPs also carries implications in terms of the commodification of curriculum and (Knight, 2015; De Vita and Case, 2003; Altbach, 2015). One issue that emerged from the analysis was the assumption and construction of students as consumers. Creating HE that is attractive for students implies that there exists a global market. This market exercises power as policy is produced. As a contrast to the market, the highlighting of Swedish as the main language in Sweden functions as a counterpart to market interests.

Although HE surely benefits from a certain degree of internationalization, the scholarly community should be cautiously skeptical towards the effects that marketization brings. Firstly, it intensifies the idea of competitiveness in regards of teaching and research. This intensification may very well lead to higher quality in both areas, but it could also be devastating for HE as a critical voice in society (Lynch, 2006; Ek et al., 2013), eventually leading to a loss of legitimacy (Taylor, 2001) and transparency (De Vita and Case, 2003). Marketization could also result in a changing role and meaning of teachers and learners (Ball, 2004; Molesworth et al., 2009) as well as the very purpose of public production of learning (Marginson, 2007). It has been argued and proposed that proficiency in Swedish will serve as a jetty, whereby careers could potentially be affected. Depending on when during an academic career facultymembers join, it could impede or support further advancements within HE structures.

Acknowledgements Open access funding provided by University of Gothenburg. To be written if accepted for publication.

\section{Compliance with Ethical Standards}

Conflict of Interest Author A declares that he/she has no conflict of interest.

Author B declares that he/she has no conflict of interest.

Ethical Approval This article does not contain any studies with human participants or animals performed by any of the authors.

Open Access This article is licensed under a Creative Commons Attribution 4.0 International License, which permits use, sharing, adaptation, distribution and reproduction in any medium or format, as long as you give appropriate credit to the original author(s) and the source, provide a link to the Creative Commons licence, and 
indicate if changes were made. The images or other third party material in this article are included in the article's Creative Commons licence, unless indicated otherwise in a credit line to the material. If material is not included in the article's Creative Commons licence and your intended use is not permitted by statutory regulation or exceeds the permitted use, you will need to obtain permission directly from the copyright holder. To view a copy of this licence, visit http://creativecommons.org/licenses/by/4.0/.

\section{References}

Altbach, P. (2015). Perspectives on internationalizing higher education. International Higher Education, 27. Auerbach, C., \& Silverstein, L. B. (2003). Qualitative data: An introduction to coding and analysis. New York: New York University Press.

Ball, S. J. (2004). Education for sale. The commodification of everything: King's Annual Education Lecture 2004.

Brandenburg, U., \& De Wit, H. (2015). The end of internationalization. International Higher Education, 62(62). https://doi.org/10.6017/ihe.2011.62.8533.

Brooks, R. (2018). Higher education mobilities: A cross-national European comparison. Geoforum, 93, 8796. https://doi.org/10.1016/j.geoforum.2018.05.009.

Candlin, C. (2006). Accounting for interdiscursivity: Challenges to professional expertise. In M. Gotti \& D. Giannoni (Eds.), New trends in specialized discourse analysis (pp. 21-45). Bern: Peter Lang.

Cardoso, S., Carvalho, T., \& Santiago, R. (2011). From students to consumers: Reflections on the marketisation of Portuguese higher education. European Journal of Education, 46(2), 271-284. https://oi.org/10.1111/j.1465-3435.2010.01447.x.

Charmaz, K. (2006). Constructing grounded theory: A practical guide through qualitative analysis: Sage.

De Vita, G., \& Case, P. (2003). Rethinking the internationalisation agenda in UK higher education. Journal of Further and Higher Education, 27(4), 383-398. https://doi.org/10.1080/0309877032000128082.

Duong, V. A., \& Chua, C. S. (2016). English as a symbol of internationalization in higher education: A case study of Vietnam. Higher Education Research \& Development, 35(4), 669-683. https://doi.org/10.1080 /07294360.2015.1137876.

Ek, A.-C., Ideland, M., Jönsson, S., \& Malmberg, C. (2013). The tension between marketisation and academisation in higher education. Studies in Higher Education, 38(9), 1305-1318. https://doi. org/10.1080/03075079.2011.619656.

Fairclough, N. (1993). Critical discourse analysis and the marketization of public discourse: The universities. Discourse \& Society, 4(2), 133-168. https://doi.org/10.1177/0957926593004002002.

Hammersley, M., \& Atkinson, P. (1995). Ethnography: Principles in practice. London: Routledge.

Hult, F. M. (2015). Nexus analysis. In F. M. Hult \& D. Cassels Johnson (Eds.), Research methods in language policy and planning: A practical guide. West Sussex: John Wiley \& Sons.

Jongbloed, B. (2003). Marketisation in higher education, Clark's triangle and the essential ingredients of markets. Higher Education Quarterly, 57(2), 110-135. https://doi.org/10.1111/1468-2273.00238.

Karlsson, S., \& Karlsson, T. S. (2019). Language policy as 'frozen' ideology: Exploring the administrative function in Swedish higher education. Current Issues in Language Planning., 21(1), 67-87. https://doi. org/10.1080/14664208.2019.1593723.

Knight, J. (2015). Internationalization brings important benefits as well as risks. International Higher Education(46), doi:https://doi.org/10.6017/ihe.2007.46.7939.

Lynch, K. (2006). Neo-liberalism and marketisation: The implications for higher education. European educational research journal, 5(1), 1-17. https://doi.org/10.2304/eerj.2006.5.1.1.

Marginson, S. (2007). The public/private divide in higher education: A global revision. Higher Education, 53(3), 307-333. https://doi.org/10.1007/s10734-005-8230-y.

Maringe, F. (2009). Strategies and challenges of internationalisation in HE: An exploratory study of UK universities. International Journal of Educational Management, 23(7), 553-563. https://doi.org/10.1108 /09513540910990799.

Mautner, G. (2005). The entrepreneurial university. A discursive profile of a higher education buzzword. Critical Discourse Studies, 2(2), 95-120. https://doi.org/10.1080/17405900500283540.

Mautner, G. (2010). Language and the market society: Critical reflections on discourse and dominance. Abingdon: Routledge.

Molesworth, M., Nixon, E., \& Scullion, R. (2009). Having, being and higher education: The marketisation of the university and the transformation of the student into consumer. Teaching in Higher Education, 14(3), 277-287. https://doi.org/10.1080/13562510902898841. 
Mwangi, C. A. G., Latafat, S., Hammond, S., Kommers, S., Thoma, H. S., Berger, J., et al. (2018). Criticality in international higher education research: A critical discourse analysis of higher education journals. Higher Education, 1-17, doi: https://doi.org/10.1007/s10734-018-0259-9.

Newman, S., \& Jahdi, K. (2009). Marketisation of education: Marketing, rhetoric and reality. Journal of Further and Higher Education, 33(1), 1-11. https://doi.org/10.1080/03098770802638226.

Poole, G. S. (2016). Administrative practices as institutional identity: Bureaucratic impediments to HE 'internationalisation'policy in Japan. Comparative Education, 52(1), 62-77. https://doi.org/10.1080 /03050068.2015.1125615.

Prop. 2004/05:162. Ny värld - ny högskola.

Robertson, S. L., \& Keeling, R. (2008). Stirring the lions: Strategy and tactics in global higher education. Globalisation, Societies and Education, 6(3), 221-240. https://doi.org/10.1080/14767720802343316.

Salö, L. (2016). Languages and linguistic exchanges in Swedish academia: Practices, processes, and globalizing markets. Stockholm: Department of Swedish Language and Multilingualism, Stockholm University.

SFS 2009:600. Språklag. In Kulturdepartementet (Ed.). Stockholm.

Siiner, M. (2016). University administrators as forced language policy agents. An institutional ethnography of parallel language strategy and practices at the University of Copenhagen. Current Issues in Language Planning, 17(3-4), 441-458. https://doi.org/10.1080/14664208.2016.1204058.

SOU 2002:27. Mål i mun. Förslag till handlingsprogram för svenska språket. In Kulturdepartementet (Ed.).

Swales, J. (1987). Utilizing the literatures in teaching the research paper. TESOL Quarterly, 21(1), 41-68. https://doi.org/10.2307/3586354.

Taylor, J. (2001). The impact of performance indicators on the work of university academics: Evidence from Australian universities. Higher Education Quarterly, 55(1), 42-61. https://doi.org/10.1111/14682273.00173 .

Publisher's Note Springer Nature remains neutral with regard to jurisdictional claims in published maps and institutional affiliations.

Tom S. Karlsson is an associate professor of public administration. He studies management and policy reform in government agencies.

Susanna Karlsson is an associate professor of Scandinavian studies. She studies micro and macro language policy and planning. 